\title{
2'-Hydroxyl Proton Positions in Helical RNA from Simultaneously Measured Heteronuclear Scalar Couplings and NOEs
}

\author{
Jinfa Ying and Ad Bax* \\ Laboratory of Chemical Physics, National Institute of Diabetes and Digestive and Kidney Diseases, \\ National Institutes of Health, Bethesda, Maryland 20892 \\ Received January 26, 2006; E-mail: bax@nih.gov
}

The ribose 2'-hydroxyl group in RNA is largely responsible for differences in structure, hydration, and thermodynamic stability relative to DNA. ${ }^{1}$ In addition to promoting the $\mathrm{C} 3^{\prime}$-endo pucker of the ribose, the $2^{\prime} \mathrm{OH}$ group provides a scaffold for the water network in the minor groove of $\mathrm{RNA}^{2}$ and plays a role in RNA catalysis. ${ }^{3,4}$ In $\mathrm{H}_{2} \mathrm{O}$ solution at low temperature, the $2^{\prime} \mathrm{OH}$ protons in doublehelical, A-form RNA can be observed by NMR, and $\mathrm{OH}$ orientations have been studied primarily on the basis of semiquantitative NOE analysis. ${ }^{1,5,6}$ Energetically, three different orientations are plausible, ${ }^{7}$ referred to as the $\mathrm{O}^{\prime}, \mathrm{O}^{\prime}$, and base domains. A very recent study by Fohrer et al. ${ }^{8}$ concludes that $\mathrm{OH}$ bond orientations alternate between the base and the $\mathrm{O}^{\prime}$ domain.

Here, we describe a novel 3D NMR experiment that simultaneously yields ${ }^{13} \mathrm{C}$-dispersed NOEs from ribose protons to $2^{\prime} \mathrm{OH}$, as well as E.COSY-type ${ }^{9} J_{\mathrm{C}-\mathrm{OH}}$ couplings. Highly reproducible and narrowly clustered ${ }^{3} J_{\mathrm{Cl}^{\prime}-2^{\prime} \mathrm{OH}}$ and ${ }^{3} J_{\mathrm{C}^{\prime}-2^{\prime} \mathrm{OH}}$, combined with quantitative evaluation of the NOEs to $2^{\prime} \mathrm{OH}$, indicates that in our system all $\mathrm{OH}$ groups predominantly occupy the base region. The pulse sequence for measurement of $J_{\mathrm{C}-\mathrm{OH}}$ is shown in Figure 1 and uses the IPAP approach ${ }^{10}$ to encode the ${ }^{3,2} J_{\mathrm{C}-\mathrm{OH}}$ couplings into the $2^{\prime} \mathrm{OH}$ resonance frequency difference in two 3D NOESY spectra, obtained from the sum and difference of an in-phase (IP) and an anti-phase (AP) type of spectrum (i.e., IP + AP and IP - AP). A description of the experiment in terms of product operator formalism is provided as Supporting Information. In brief, a constant-time ${ }^{1} \mathrm{H}-{ }^{13} \mathrm{C}$ element (time points $a-f$ ) precedes the NOE mixing period, $\tau_{\mathrm{m}}$, which is followed by WATERGATE ${ }^{11}$ detection. Depending on whether the dashed $180^{\circ}{ }^{13} \mathrm{C}$ pulse at the midpoint of the ${ }^{1} \mathrm{H}-\left\{{ }^{13} \mathrm{C}\right\}$ rephasing interval is applied or not, the detected $\mathrm{OH}$ proton is either antiphase or in-phase with respect to the ribose ${ }^{13} \mathrm{C}$ on whose attached ${ }^{1} \mathrm{H}$ the magnetization originated at time point $a$. In the usual IPAP manner, ${ }^{10}$ the sum and difference of the two spectra yield the individual $2^{\prime} \mathrm{OH}-\left\{{ }^{13} \mathrm{C}\right\}$ doublet components, and coupling constants between the $2^{\prime} \mathrm{OH}$ proton and the ribose carbons can be extracted from their frequency difference. The measured splittings, in principle, can be reduced by ${ }^{13} \mathrm{C}$ spin flips during $\tau_{\mathrm{m}}$ and detection, ${ }^{12}$ but not by solvent exchange of the $2^{\prime} \mathrm{OH}$. Considering that the ${ }^{13} \mathrm{C}$ $T_{1}$ relaxation time exceeds the sum of $\tau_{\mathrm{m}}$ and the $t_{3}$ detection period by more than an order of magnitude, such reduction is negligible, however. For highest $\mathrm{S} / \mathrm{N}$, the intensities of NOEs between the $2^{\prime} \mathrm{OH}$ and the ribose protons are obtained from the IP spectrum only; due to partial cancellation of the anti-phase $2^{\prime} \mathrm{OH}-\left\{{ }^{13} \mathrm{C}\right\}$ doublet components, the AP spectrum is much weaker.

The favorable relaxation properties of multiple quantum coherence, ${ }^{13}$ applicable during the $25 \mathrm{~ms}{ }^{13} \mathrm{C}$ chemical shift labeling, and ${ }^{1} J_{\mathrm{CC}}$ decoupling resulting from constant-time evolution result in good sensitivity and ${ }^{13} \mathrm{C}$ resolution. Importantly, the ribose ${ }^{1} \mathrm{H}$ chemical shift is recorded simultaneously during this ${ }^{13} \mathrm{C}$ evolution period $^{14}$ and its preceding and following $\delta$ delays, yielding a 31 ms constant-time sampling of ribose ${ }^{1} \mathrm{H}$ evolution without incurring

8372 a J. AM. CHEM. SOC. 2006, 128, 8372-8373

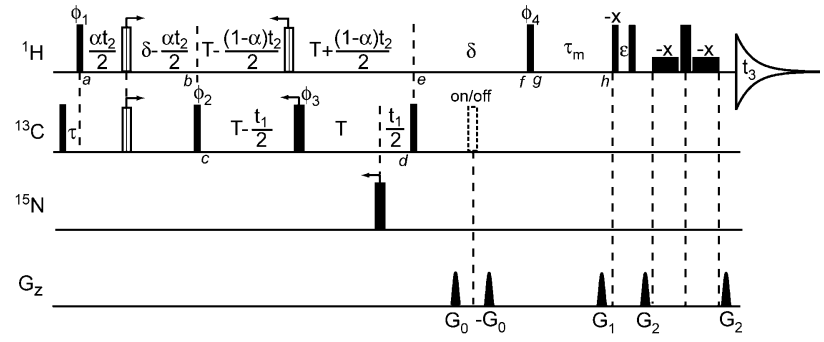

Figure 1. Three-dimensional constant-time HMQC-IPAP-NOESY pulse sequence. Details regarding delays, etc., are presented in the Supporting Information.

any additional relaxation losses. $J_{\mathrm{HH}}$ and multi-bond $J_{\mathrm{CH}}$ and $J_{\mathrm{CC}}$ couplings remain active during these constant-time evolution periods, but appropriate correction factors are derived from the relative intensities of "diagonal" resonances observed for the various ribose protons (Supporting Information).

The experiment of Figure 1 was applied to a $1.0 \mathrm{mM}$ solution of a uniformly ${ }^{13} \mathrm{C} /{ }^{15} \mathrm{~N}$-enriched oligomer $(10 \mathrm{mM}$ phosphate buffer, $\mathrm{pH}$ 6.8, $10 \mathrm{mM} \mathrm{NaCl}, 0.02 \mathrm{mM}$ EDTA, 95\% $\left.\mathrm{H}_{2} \mathrm{O} / 5 \% \mathrm{D}_{2} \mathrm{O}\right)$, derived from helix-35 of E. coli $23 \mathrm{~S}$ ribosomal RNA (Figure 2) at $6{ }^{\circ} \mathrm{C}$ and $800 \mathrm{MHz}$. The exchange rate constants of the $2^{\prime} \mathrm{OH}$ protons with bulk water, measured from a series of 2D NOESY experiments at $6{ }^{\circ} \mathrm{C}$ in which the $2^{\prime} \mathrm{OH}$ proton magnetization is pre-inverted, were found to range from $18 \mathrm{~s}^{-1}$ for C758 to $52 \mathrm{~s}^{-1}$ for G738 (Supporting Information). The IP 3D NOESY spectrum shows relatively strong NOEs from the intra-ribose $\mathrm{H}^{\prime}$ to $2^{\prime} \mathrm{OH}$ protons (Figure 2A). On average, somewhat weaker NOEs from $2^{\prime} \mathrm{OH}$ to $\mathrm{H}^{\prime}$ are observed, but NOEs from $2^{\prime} \mathrm{OH}$ to $\mathrm{H}^{\prime}{ }^{\prime}$ and $\mathrm{H}^{\prime}$ are much weaker or absent (Supporting Information). Fast exchange between $2^{\prime} \mathrm{OH}$ protons and water in the loop region prevented measurement of their NOEs. The couplings between the $2^{\prime} \mathrm{OH}$ protons and $\mathrm{C2}^{\prime}$ or $\mathrm{C}^{\prime}$ are readily measured from the frequency difference in the 2 'OH dimension $\left(F_{3}\right)$ of the 3D constant-time HMQC-IPAPNOESY spectrum (Figure 2). The coupling constants between the $2^{\prime} \mathrm{OH}$ protons and the ribose carbons are remarkably similar for the different riboses. For example, ${ }^{2} J_{\mathrm{C} 2^{\prime}-2^{\prime} \mathrm{OH}}$ values all fall in the -2.2 to $-3.3 \mathrm{~Hz}$, indicative of the high precision at which these couplings can be measured. Three-bond couplings to $\mathrm{Cl}^{\prime}$ are also very uniform and small $(1.3 \pm 0.7 \mathrm{~Hz}$, Supporting Information) indicative of a gauche conformation. ${ }^{8}$ The very weak intensity of the $\mathrm{H}^{\prime}{ }^{\prime}$ to $2^{\prime} \mathrm{OH} \mathrm{NOE}$ prohibits precise measurement of ${ }^{3} J_{\mathrm{C} 3^{\prime}-2^{\prime} \mathrm{OH}}$ from the 3D constant-time HMQC-IPAP-NOESY HMBC spectrum. Instead, these values were measured from quantitative HMBC experiments ${ }^{16}$ (Supporting Information). Measured values are again quite uniform $(4.2 \pm 0.7 \mathrm{~Hz})$ and much larger than ${ }^{3} J_{\mathrm{Cl}^{\prime}-2^{\prime} \mathrm{OH}}$ (Table $2 \mathrm{~S}$ ), in agreement with the relative trend of these couplings recently reported by Fohrer et al. ${ }^{8}$ In comparison to this study, much less variation in our ${ }^{3} J_{\mathrm{C}-\mathrm{OH}}$ couplings is seen, which may in part derive 


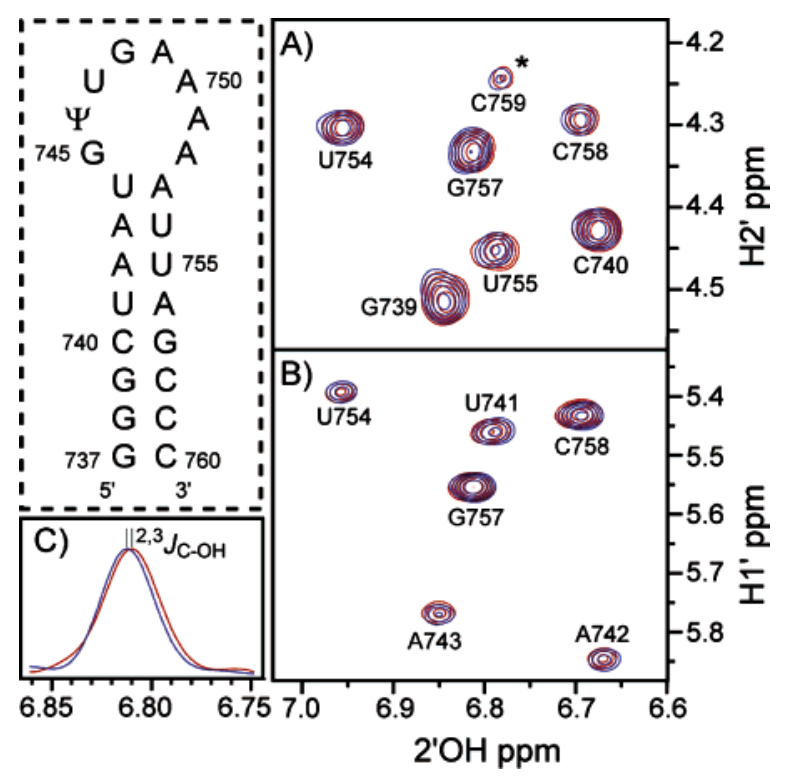

Figure 2. Projections of selected regions of the 3D constant-time HMQCIPAP-NOESY spectrum (40 ms mixing), recorded at $800 \mathrm{MHz}$, using a cryogenic triple-resonance probehead, for the RNA oligomer shown in the dashed box. $F_{1}$ projections corresponding to (A) $\mathrm{C} 2$ ' between 75 and 75.5 ppm and (B) $\mathrm{Cl}^{\prime}$ between 92.3 and 92.9, 93.6 and $93.9 \mathrm{ppm}$. Asterisks mark peaks just outside these projected regions and therefore are weaker. Red and blue contours represent the doublet components obtained from the IP + AP and IP - AP spectra, respectively. They are displaced in the $F_{3}\left(2^{\prime} \mathrm{OH}\right)$ dimension by ${ }^{2} J_{\mathrm{C}^{\prime}-2^{\prime} \mathrm{OH}}(\mathrm{A})$ and ${ }^{3} J_{\mathrm{C}^{\prime}-2^{\prime} \mathrm{OH}}(\mathrm{B})$, as illustrated in the $1 \mathrm{D}$ trace in $(\mathrm{C})$. Total acquisition time was $82 \mathrm{~h}$.

from the unique ability of E.COSY experiments to accurately measure minute or even zero couplings that are not affected by the highly non-uniform $\mathrm{OH}$ solvent exchange rates (Table $1 \mathrm{~S}$ ) or may result from the difference in the system studied. The relative size of ${ }^{3} J_{\mathrm{C} 3^{\prime}-2^{\prime} \mathrm{OH}}$ and ${ }^{3} J_{\mathrm{Cl}^{\prime}-2^{\prime} \mathrm{OH}}$ suggests that the $2^{\prime} \mathrm{OH}$ groups in A-form RNA duplexes are oriented toward either the base domain (i.e., approximately trans to $\mathrm{C}^{\prime}$ but gauche to $\mathrm{C}^{\prime}$ ) or a small region of the $\mathrm{O}^{\prime}$ domain (i.e., $2^{\prime} \mathrm{OH}-\mathrm{O} 2^{\prime}-\mathrm{C} 2^{\prime}-\mathrm{H} 2^{\prime}$ dihedral angle $>120^{\circ}$ ) and excludes significant occupation of the ${ }^{\prime} 4^{\prime}$ domain. ${ }^{6,8}$ The ambiguity between the base and $\mathrm{O}^{\prime}$ ' domains can be resolved by quantitative analysis of the $2^{\prime} \mathrm{OH}$ NOEs, also available from the experiment of Figure 1.

The high resolution in the indirect ${ }^{1} \mathrm{H}$ and ${ }^{13} \mathrm{C}$ dimensions of the 3D constant-time HMQC-IPAP-NOESY spectrum strongly reduces overlap compared to 2D NOESY spectra and permits unambiguous assignment and analysis of the $2^{\prime} \mathrm{OH}$ NOE crosspeaks. In addition to the NOEs from $\mathrm{H}^{\prime}$ and $\mathrm{H}^{\prime}$ to $2^{\prime} \mathrm{OH}$, discussed above, weak NOEs between $2^{\prime} \mathrm{OH}$ and the intra-nucleotide $\mathrm{H}^{\prime}$ protons are observed, whereas for eight nucleotides the $\mathrm{H}^{\prime}-2^{\prime} \mathrm{OH}$ NOEs also are above the signal-to-noise threshold. Although NOE intensities to $2^{\prime} \mathrm{OH}$ are differentially affected by evolution of $J$ couplings during the constant-time evolution period in the pulse scheme of Figure 1, correction factors can be derived from resolved "diagonal" ${ }^{13} \mathrm{C}-{ }^{1} \mathrm{H}$ correlations in the $3 \mathrm{D}$ spectrum, and within the A-form helix are found to be quite uniform for a given type of carbon (Supporting Information). Comparing these corrected NOE intensities to the $\mathrm{H}^{\prime}-2^{\prime} \mathrm{OH} \mathrm{NOE}$ indicates that $\mathrm{H}^{\prime}-2^{\prime} \mathrm{OH}$ is $1.6-$ 3.5-fold stronger, whereas $\mathrm{H}^{\prime}-2^{\prime} \mathrm{OH}$ and $\mathrm{H}^{\prime}-2^{\prime} \mathrm{OH}$ are weaker by factors in the ranges of $0.1-0.4$ and $0.2-0.5$, respectively (Table $3 \mathrm{~S})$. Comparison of these normalized NOE intensities with values expected as a function of the $2^{\prime} \mathrm{OH}-\mathrm{O} 2^{\prime}-\mathrm{C} 2^{\prime}-\mathrm{H} 2^{\prime}$ dihedral angle (Supporting Information) indicates that the base domain is the only one where all the experimental NOEs are compatible with the calculated values, although low level occupation $(\leq 20 \%)$ of the other domains cannot be excluded. These NOE-derived results resolve the conformational ambiguity associated with the observation of very small ${ }^{3} J_{\mathrm{C1}^{\prime}-2^{\prime} \mathrm{OH}}$ values and relatively large ${ }^{3} J_{\mathrm{C}^{\prime}-2^{\prime} \mathrm{OH}}$ couplings. The presence of $2^{\prime} \mathrm{OH}$ groups predominately in the base region is perfectly compatible with the oxygen electron density seen for H-bond accepting water molecules in the minor groove of an A-form RNA helix, observed by X-ray crystallography. ${ }^{2}$

The 3D constant-time HMQC-IPAP-NOESY experiment takes advantage of overlapping, simultaneous ${ }^{1} \mathrm{H}$ and ${ }^{13} \mathrm{C}$ evolution periods and offers remarkably well-resolved 3D NOE spectra that permit measurement of $J$ couplings through the E.COSY principle. The experiment can be readily adapted for the measurement of other NOEs and $J$ couplings in both nucleic acids and proteins.

Acknowledgment. We thank Alexander Grishaev (NIH) for helpful discussions, Ed Nikonowicz (Rice University) for the helix35 RNA sample, and Frank Delaglio (NIH) for technical assistance. This work was supported by the Intramural Research Program of the NIDDK, NIH, and by the Intramural Antiviral Target Program of the Office of the Director, NIH.

Supporting Information Available: Four tables with 2'OH solvent exchange rate constants, ${ }^{3,2} \mathrm{~J}_{\mathrm{C}-2^{\prime} \mathrm{OH}}$ coupling constants, and normalized experimental NOEs from HMQC - and HSQC-NOESY spectra; two figures for the projected planes $\left(\mathrm{C}^{\prime} / \mathrm{C}^{\prime} / \mathrm{C}^{\prime}\right)$ of the HMQC - and HSQC-NOESY; one figure for the pulse sequence and spectra of quantitative $\mathrm{HMBC}$; one figure displaying interproton distances and corresponding NOE ratios calculated as a function of the $2^{\prime} \mathrm{OH}-\mathrm{O} 2^{\prime}-$ $\mathrm{C} 2^{\prime}-\mathrm{H} 2^{\prime}$ dihedral angle; product operator formalism analysis and detailed parameters of the pulse scheme of Figure 1; derivation of NOE correction factors for the effect of passive couplings. This material is available free of charge via the Internet at http://pubs.acs.org.

\section{References}

(1) Gyi, J. I.; Lane, A. N.; Conn, G. L.; Brown, T. Nucleic Acids Res. 1998, $26,3104-3110$

(2) Egli, M.; Portmann, S.; Usman, N. Biochemistry 1996, 35, 8489-8494.

(3) Eckstein, F., Lilley, D. M. J., Eds. Catalytic RNA; Springer-Verlag: Berlin, 1996.

(4) Gesteland, R. F.; Cech, T. R. In The RNA World; Gesteland, R. F., Cech, T. R., Atkins, J. F., Eds.; Cold Spring Harbor Laboratory Press: Cold Spring Harbor, NY, 1998.

(5) Lynch, S. R.; Pelton, J. G.; Tinoco, I., Jr. Magn. Reson. Chem. 1996, 34 S11-S17.

(6) Hennig, M.; Fohrer, J.; Carlomagno, T. J. Am. Chem. Soc. 2005, 127, $2028-2029$.

(7) Auffinger, P.; Westhof, E. J. Mol. Biol. 1997, 274, 54-63.

(8) Fohrer, J.; Hennig, M.; Carlomagno, T. J. Mol. Biol. 2006, 356, 280287.

(9) Griesinger, C.; Sørensen, O. W.; Ernst, R. R. J. Am. Chem. Soc. 1985 107, 6394-6396.

(10) Ottiger, M.; Delaglio, F.; Bax, A. J. Magn. Reson. 1998, 131, 373-378.

(11) Piotto, M.; Saudek, V.; Sklenár, V. J. Biomol. NMR 1992, 2, 661-665.

(12) Harbison, G. S. J. Am. Chem. Soc. 1993, 115, 3026-3027.

(13) Griffey, R. H.; Redfield, A. G. Q. Rev. Biophys. 1987, 19, 51-82.

(14) Pervushin, K.; Eletsky, A. J. Biomol. NMR 2003, 25, 147-152.

(15) Plateau, P.; Guéron, M. J. Am. Chem. Soc. 1982, 104, 7310-7311.

(16) Zhu, G.; Live, D.; Bax, A. J. Am. Chem. Soc. 1994, 116, 8370-8371. JA0606226 